\title{
Training of Future Civil Engineers in the Area of Foreign Language: Interaction of Educational Paradigms
}

\author{
Irina Nordman ${ }^{1,}{ }^{*}$ and Elena Molodykh-Nagaeva ${ }^{1}$ \\ ${ }^{1}$ Industrial University of Tyumen, 625000, Volodarskogo-str., 38, Russia
}

\begin{abstract}
The article deals with problems of engineers' training in higerh school. Problems in the organization of classroom and students' independent work, in the area of evaluation and control as well as teaching recourses and training methods are pointed out. The role of foreign language in the training of future specialists in the field of construction is highlighted. The necessity of the use of settings of traditional and innovative educational paradigms when training of students in the specialization "Industrial and civil construction" on the discipline "Foreign Language" is proved. The interaction of traditional and innovative teaching resources, trraining methods, as well as evaluation and control means is shown. The conclusions on the effectiveness of interaction of traditional and innovative educational concepts when teaching a foreign language in technical universities are drawn.

Key words: innovative educational paradigm, foreign language in technical university, competence paradigm, evaluation and control, student-oriented paradigm, training methods, teaching resources, traditional educational paradigm.
\end{abstract}

\section{Introduction}

The problem of graduate training in the area of construction and their competitiveness is extremely important for development of Russian education. The existing system of higher education is no longer able to develop the old way due to Russia's entry into the Bologna process, development and strengthening of international relations, increasing business activity of the population, processes of globalization and other phenomena of contemporary reality.

The successful solution of this problem requires to take into account the causes of the shortcomings of the engineers' training. In scientists'papers, lack of time for teachers for scientific and methodical work, for personal communication with students and for updating the content of lessons are emphasized. [1-3]. Causes of reducing the quality of training are reduce the period of renovation of information, its obsolescence even before the completion of the education cycle; changes in the labor market priorities, where specialist are required not so much knowledge as competence package. There are also imperfection

*Corresponding author: nordman.i@inbox.ru 
of the educational programs and technologies, the retard of quality of graduates' training from requirements of fast-growing science and industry, the emergence of new technologies, which should be based primarily on interdisciplinary knowledge, reduction of cultural and linguistic competence of higher school graduates [4]. The above mentioned problems occur in all training areas, including the foreign language.

The leading role in enhancing and preserving the language competence belongs to the discipline "Foreign language", "Business Foreign Language", "Technical Foreign Language". Foreign language plays currently a major role in establishing Russia's contacts with partner countries, including those in the construction industry. Today, when the world is gradually moving towards bilingualism (bilingual) [5], the role of foreign language in a training program for future specialists - graduates of construction higher school -increased significantly in our country. Good level of foreign language proficiency is a precondition for getting a promising job. Foreign language becomes a structural component of the model engineer training, because it is a prerequisite for the implementation of one of the most important principles of the Bologna process - the principle of academic and professional mobility.

Disciplines "Foreign Language", "Business Foreign Language", "Technical Foreign Language" should be an integral part of the engineers' training system. This is connected not only with the opportunities, which it offers for the development of communicative abilities of future engineers, but also with increased academic mobility, the increasing role of international relations and the fact that the vast amount of information is currently available only in a foreign language [6].

Today, graduates of technical universities are required fundamental knowledge in the professional field, the ability to establish links between professional knowledge and other areas, the ability to successfully participate in the international foreign language communication, both orally and in written form [7]. Modern employer needs today not only civil engineers whose knowledge is based on theoretical one but responsible professionals, who are able to think independently, have search, information processing and communication skills in native and foreign languages.

Problems of training students in the area of foreign language are found first of all at the level of training plans and working programs. The study of basic specialty begins from the third year, whereas foreign language training is intended for two study years, therefore, students lack the specialized knowledge and personal professional experience. Also in the first year, students only learn basic vocabulary and grammar material and translate mainly educational texts. But effective engineer training involves learning to read scientifictechnical and specialized texts, which requires the ability to move from one reading strategy to another [8]. In the second year the transition from educational to the authentic specialized texts is significantly difficult due to complex grammatical structures, terminology, professionally-oriented language, not equivalent words requiring translation using translation transformations [9]. An additional problem is the insufficient number of hours provided by the working program.

Problems in the organization of educational process in students' independent work are observed in the imbalance between the comprehensive capabilities of independent work and its actual implementation. This is manifested in the absence of developed methods, techniques and technologies of self-study, as well as insufficient attention to teachers and scientists to question of their systemic application [10].

The reasons for the problems of students' training from in the field of evaluation and control are subjectivity of traditional control systems, absence of means of objective control and the scientists' consensus about the functions and types of control as well as inability to make measurements associated with the personality of the learner [11]. 
The above mentioned factors have a negative impact on the level of graduates' training of construction higher schools in the area of foreign language training. Thus, the traditional system of engineering specialties' training in the area of foreign language caused at present a contradiction between the social control of the construction profile professionals and state requirements for professional competence and personal qualities of the graduates.

From the analysis of the listed problems of training of civil engineers follows that changes are needed, especially at the level of the educational process (in the field of classroom, students' independent work, assessment and monitoring tools, teaching resources and training methods). Scientists also emphasizes the need to take into account the personal characteristics of students at all stages of the learning process, and ultimately the general reorientation of the educational process on the personality of student. Accumulated knowledge dosn't become increasingly important. Instead of this, the acquisition through personal knowledge of a particular set of competencies is required. Consideration the training degree at a personal level becomes increasingly important today. It is necessary to go beyond the narrow professional approach to higher education, transfer to the consideration of education as an essentially continuous one, throughout a person's life. All this indicates the impossibility of solving the urgent problems by means of the former educational system. Supplement the settings of traditional educational paradigm with frameworks of innovative educational concepts could be solution.

Further, we will consider the use of both traditional and innovative frameworks in the field of organization of classroom and students' independent work, in teaching resources, training methods as well as evaluation and control means in students' foreign language training in the specialization "Industrial and Civil Engineering" in Tyumen Industrial University.

\section{Methods}

Training manual "Construction and Civil Engineering" [12], as well as methodical guidelines for students in the specialization "Industrial and civil construction" $[13,14]$ are used on practical lessons on disciplines "English as a Foreign Language", "Technical English Language", "German as a Foreign Language" "Technical German Language".

They are developed for the purpose of formation of students' ability to read and translate the original unadapted literature in their specialty, to expand the terminological vocabulary, to develop speech skills and encourage independent search activity in the process of language training. The training manual and methodical guidelines include texts for translation and various reading kind, an extensive vocabulary, lexical and grammatical exercises, communicative tasks. When developing the training manual and methodical guidelines, original printed and electronic sources were used. The above mentioned teaching resources were developed in accordance with the principles of authenticity, problem relevance and alternative decision making [15].

The mentioned teaching resources are being actively used in the classroom practical lessons, which are held in the traditional (group) form. Introduction to the topic takes place in the process of repetition and/or mastering of vocabulary for the studied subject.

The form of conducting the classroom work appropriates the settings of traditional, cognitive educational concept. At the level of lesson goals, frameworks of innovative educational concepts appear, expressed not merely by the acquisition of scientific knowledge but the ability to properly analyze and apply information. On the motivation level, students' interest in the studied subject can be noted, due to the coupling of the material being studied with their future profession, which is a manifestation of innovative, competency educational paradigm. 
The principal activities at the beginning of topic study are acquaintance with the specialized vocabulary and translation of authentic technical text with preliminary explanation of rules for the use of specialized terminology. Teaching methods of traditional, cognitive educational paradigm (information-receptive and reproductive ones) are used here. Then students try to estimate the translation adequacy of the specialized text and ask the teacher for help only in case of difficulty. It contributes to the development of cognitive activity, creativity and self-actualization, which is typical for an innovative, student-centered educational concept.

Students' independent work is organized with the help of traditional and innovative means of teaching. Homework on the subject can be mastering of a significant amount of specialized vocabulary, exercises to consolidate the grammatical phenomena occurring in the texts topic being studied (traditional educational paradigm). Then practical focus activities follow. There are schematic bridges description of given design and selection of building materials for them, choice of the roof kind as well as building material for walls and flooring material for a given structure. Next, a justification of choice is made, based on the general principles of the construction for such structures, including the direction of the acting forces, as well as the properties of materials and structures destination. Such tasks correspond to the principle of relevance of the problem, which means the practical significance of making of the listed above tasks for future civil engineers. The principle of alternative decisions manifests here, which means the ability to find non-standard solutions. Such tasks indicate the settings of competence educational paradigm.

For doing homework, elements of competence educational paradigm are primarily used, where students show not only the degree of mastering the material, but also the ability to apply this knowledge in practice [16]. For homework, students can not only use traditional means of teaching (printed training manual and methodical guidelines). Necessary information, in particular the reference one, they can also find in numerous specialized internet resources on the websites of known construction companies representing the world experience in the field of construction. These resources are invaluable in preparing students' reports for the scientific and technical conference in a foreign language; the participation in technical conferences is also an integral part of the bachelors' training in the area of construction [17]. In addition, to train the separate grammatical phenomena, students can use training tests in an electronic system supports the educational process. However, they can individually choose the grammatical phenomena that they need to repeat and to make the necessary number of test attempts. The mentioned reflects settings of innovative personality-oriented educational paradigm.

In the area of evaluation and control, homework assessment as well as control of the subsequent tasks, related to the usage rules of highly specialized vocabulary are primarily conducted by teacher. Both students and teacher can take part in evaluating the adequacy of the translation of the specialized authentic text. The control of the practical focused homework can be carried out by students' group during the discussion of description and choice justification of structures and materials.

\section{Results and discussion}

Interaction of elements of traditional and innovative educational concepts in teaching the discipline "Foreign Language" in the area of construction is observed in the organization of classroom and students' independent work, in the goals of conducting classes, in the area of students' motivation, in the teaching methods and resources, as well as evaluation and control. The interaction of traditional and innovative educational concepts of the foreign language training is already manifested at the level of goals of developed training materials. They include both settings of the traditional approach (the formation of the ability to read 
and translate the original unadapted specialized literature, to expand the specialized vocabulary), and innovative one (development of speech skills, encouraging of self-search activity in the process of the language training).

These teaching resources solve the problem of information update in a foreign language in the field of construction. They are based on today's authentic sources, reflecting the trends of the construction industry in the leading countries of the world.

In the area of content, the training manual and methodic guidelines include the texts for translation and different kinds of reading, an extensive vocabulary, lexical and grammatical exercises (in accordance with traditional educational paradigm), as well as communication tasks of problematic nature as well as creative and practical tasks (in accordance with innovative concepts of education).

In the period of use (2014-2016) of the above mentioned teaching materials as well as the possibilities of electronic support system of educational process, students had stable absolute performance in the intermediate control on the discipline:

$2016-100 \%$,

$2015-90 \%$,

$2014-88 \%$.

During studying the discipline, students used not only traditional teaching resources (manual and guidelines), but also the innovative ones (Internet-sources and capabilities of the electronic system). The electronic support system of educational process showed the statistics that the vast majority of students (about 95\%) used the proposed training tasks and exercises. Indicators of current performance of students who had completed a sufficient number of tasks for self-training and control were by approximately $30 \%$ higher than those in comparison with the students, not fulfilled them [18]. In the area of control, a combination of traditional methods of its carrying (assessment of vocabulary knowledge, correctness of translation by teacher) and innovative ones (results discussion in the group, the mutually evaluation of the performed tasks, evaluation by the electronic system) is observed. Use of the teaching resources, as well as evaluation and control means, representing the traditional educational concept and innovative educational concepts may contribute to the optimization of the educational process when teaching the discipline.

\section{Conclusion}

The foreign language training in today's technology (construction) area is intended to reflect the labor market needs and to realize the aspirations of the students to learn a foreign language for a future career in the chosen field of construction. In this connection, it is advisable to timely respond to labor market needs, carrying out the educational process with the maximum use of innovations, at the same time preserving the traditional elements of the proven educational concepts.

\section{References}

1. G.A. Shabanov, The quality of education in the non-state higher school, Pedagogika, 6, 58-65 (2004)

2. Yu.P. Vetrov, T.A. Maiboroda, Vysshee obrazovanie v Rossii, 5, 48-50 (2003)

3. URL:

http://www.worldacademy.org/files/UCB/The Evolution_of the Educational_Paradi gm by C.E.Lindgren.pdf.

4. N. Salnikov, S. Burukhin, Vysshee obrazovanie v Rossii, 2, 3-11(2008) 
5. E.V. Bessonova, O.A. Shvetsova, Uniform All-Russia Scientific Bulletin, VI, 45-48(2016)

6. A.V. Tsepilova, TSPU Bulletin, 1 (178), 87-92 (2017)

7. E.M. Voronova, Bulletin of Kharkiv National Automobile and Highway University, 29 (2005)

8. I.A. Zimnyaya, Russia in the Bologna process: achievements, problems, prospects. Proceedings of the methodological seminar, Moscow, (2004)

9. T.V. Popova, PhD Thesis, St. Petersburg, (2008)

10. S.V. Mamporiya, Vysshee obrazovanie segodnya, 11, 57-59 (2010)

11. A.V. Matienko, PhD Thesis, Irkutsk, (2008)

12. Zh.A. Kozhan, Constuction and Civil Engineering. Training manual, (Tyumen, 2014)

13. O.M. Ivanova, S.G. Samoilenko, Metodological Guidelines for practical lessons (Tyumen, TyumGNGU, 2013)

14. E.G. Molodykh-Nagaeva, Metodological Guidelines for organization (Tyumen, TyumGNGU, 2012)

15. URL: http://7universum.com/ru/psy/archive/item/2055

16. E.G. Molodykh-Nagaeva, I.B. Nordman, Theory and Practice of Social Development, № 20, (2015). Pp. 298-300.

17. O.A. Shvetsova, Bulletin of MSUCE, 4 (2012)

18. I.B. Nordman, Mir nauki, kultury, obrazovaniya, 6 (55), 34-36 (2015) 